\title{
Pragmatic implementation research study for In Our DNA SC: a protocol to identify multi-level factors that support the implementation, adaptation, and sustainment of a population-wide genomic screening initiative in diverse populations
}

Caitlin G. Allen ( $\sim$ allencat@musc.edu )

Medical University of South Carolina

Research Article

Keywords:

Posted Date: January 28th, 2022

DOI: https://doi.org/10.21203/rs.3.rs-1298933/v1

License: (9) (1) This work is licensed under a Creative Commons Attribution 4.0 International License. Read Full License 


\section{Abstract}

\section{Background}

In 2021, the Medical University of South Carolina (MUSC) partnered with Helix, a population genetic testing company, to offer population-wide genomic screening for CDC Tier 1 conditions to 100,000 individuals in South Carolina. We developed an implementation science protocol to study the multi-level factors that influence successful implementation of the In Our DNA SC initiative.

\section{Methods}

We will use a convergent parallel mixed-methods study design to evaluate the implementation of planned strategies and associated outcomes for In Our DNA SC. Aims focus on monitoring participation to ensure engagement of racially and ethnically diverse populations, assessing contextual factors that influence implementation in community and clinical settings, describing implementation work group facilitators and barriers, and tracking program adaptations. We report details about each data collection tool and analyses planned, including: surveys, interview guides, and tracking logs to capture and code work group meetings, adaptations, and technical assistance needs.

\section{Discussion}

The goal of In Our DNA SC is to provide population-level screening for actionable genetic conditions and to foster ongoing translational research. The use of implementation science can help better understand how to support the success of In Our DNA SC, identify barriers and opportunities associated encountered during the implementation of strategies to promote In Our DNA SC to various audiences, and can insure the sustainability of population-level genetic testing. The model-based components of our implementation science protocol can support identification of best practices to streamline the expansion of similar population genomics programs at other institutions

\section{Introduction}

Genetic information can help personalize disease prevention and early detection efforts, leading to better clinical and population health outcomes. ${ }^{1,2}$ The Centers for Disease Control and Prevention (CDC) recognizes three genetic conditions: hereditary breast and ovarian cancer (HBOC) syndrome, Lynch syndrome (LS), and familial hypercholesterolemia (FH) as "Tier 1" conditions. A Tier 1 designation indicates that there is sufficient evidence and established interventions are available to reduce morbidity and mortality of individuals who are identified with these conditions. Combined, Tier 1 conditions affect $1-2 \%$ of the US population; however, few know their risk or receive information about their genetic condition at the time of disease diagnosis. ${ }^{3-6}$

Screening for Tier 1 conditions has commonly occurred through family history collection with follow-up genetic testing recommended among individuals who have a strong family history. Several barriers exist to collecting family health information that can be used to inform clinical practice, resulting in less than one-third of the population being knowledgeable of their family history. ${ }^{7-11}$ In addition to the logistical challenges associated with collecting family health history, this approach may not provide the necessary information to identify 
individuals at high genetic risk. For example, a recent population-wide genomic screening effort for the BRCA1/2 variant (associated with $\mathrm{HBOC}$ ) improved the identification of individuals with deleterious variants. Approximately $50 \%$ of individuals in these studies did not have a personal or family history that would indicate an increased risk for cancer. ${ }^{3,12}$

Although population genetic screening is a departure from traditional approaches to incorporating genetics into clinical practice, the rapidly decreasing cost of genetic sequencing and increased throughput ability have paved the way for this population-based approach. ${ }^{13,14}$ Growing evidence supports population-wide genomic screening for Tier 1 conditions among healthy adults with or without personal or family history, ${ }^{14}$ including in historically underrepresented populations. ${ }^{15}$ Indeed, in 2018, the Genomics and Population Health Action Collaborative, an ad hoc collaboration with the Roundtable on Genomics and Precision Health at the National Academy of Medicine, developed a roadmap for the implementation of population-wide genomic screening programs. ${ }^{16}$ This report further emphasizes the utility of screening for Tier 1 conditions and urges thoughtful implementation with clear strategies to evaluate the impact of these approaches in the context of medicine and society. ${ }^{16}$ In order to meet the needs of the rapidly evolving field of genetic testing, the Roundtable has recently updated its strategic plan, which includes educating the genomics/precision health workforce, increasing awareness for the power of genomics/precision health, informing policy decisions, improving data infrastructure and the evidence base, as well as issues related to ethical, legal, and social implications (ELSI) and diversity, equity, and inclusion (DEI). ${ }^{15}$ In Our DNA SC was designed with these issues in mind.

Despite the increasing accessibility of population-wide genomic screening for Tier 1 conditions in health systems, challenges exist to scaling up these efforts, including engaging large multidisciplinary teams of researchers and clinicians, ensuring participant's understanding of genetic information, equitable access and participation in population testing, and sustainability of programs. ${ }^{16-19}$ Strategies from implementation science can help address these challenges and support the integration of the genomic information captured by population screening in health systems. ${ }^{20}$ Implementation science can help identify successful implementation strategies and provide lessons learned about fundamental elements of population-wide genomic screening programs that influence support delivery of similar programs across diverse health systems. ${ }^{21}$

\subsection{Description of In Our DNA SC Partnership and Guiding Framework}

In 2021, the Medical University of South Carolina (MUSC) partnered with Helix, a leading population genomics company, to offer population-level genetic testing to participants in South Carolina. This partnership, called In Our DNA SC, is designed to provide genetic testing for up to 100,000 people by 2025 , initially reporting pathogenic or likely pathogenic variants in CDC Tier 1 conditions (APOB, BRCA1, BRCA2, EPCAM, LDLR, LDLRAP1, MLH1, MSH2, MSH6, PCSK9, PMS2). In Our DNA SC involves recruitment, consent, collection of a saliva sample, processing the sample through the Helix laboratory, receipt of results (positive and negative results), and genetic counseling for participants who receive positive results. The program involves several work groups that are co-led by MUSC and Helix to oversee essential elements of the program, including: marketing and communications, data and technology to recruit participants and return results, operations and staff training, clinical services, and research enablement to support future use of data among MUSC researchers. In Our DNA SC also established an Implementation and Evaluation Research Work Group to create 
a strategy to assess implementation, service, and clinical outcomes related to the program using principles of implementation science.

We use the Implementation Research Logic Model (IRLM) to provide a structure for describing how determinants, implementation strategies, and mechanisms of change influence outcomes related to In Our DNA SC. The IRLM comprehensively documents all potential determinants of implementation among stakeholder groups and links them to corresponding levels of outcomes to be assessed throughout the program. Our conceptual model incorporates determinants from the Consolidated Framework for Implementation Research (CFIR) among participants/community members, implementation teams within MUSC, and providers and staff at clinical sites. CFIR was designed as a comprehensive framework to describe multi-level implementation determinants in five domains: intervention characteristics, inner setting, outer setting, characteristics of the individual, and process. ${ }^{22}$

In Our DNA SC currently plans a multi-phased implementation approach, which includes a pilot phase (10 clinical sites), followed by institutional expansion across all clinical sites at MUSC and community expansion to patients not currently affiliated with MUSC. Implementation strategies associated with each phase include planning (e.g., developing charters and formal implementation blueprints, identifying, and preparing champions), quality management (e.g., tracking systems, centralizing technical assistance), education (e.g., distribution of technical assistance materials, conducting ongoing trainings), and restructuring to support scale-up. Associated mechanisms will also be evaluated to assess programmatic outcomes occur among participants (e.g., raising awareness, improving reach), implementation teams (e.g., clarifying roles and ensuring accountability), and providers and staff at implementation sites (e.g., facilitating uptake at clinical sites, having supportive staff that can answer participant questions). ${ }^{23}$

We will evaluate implementation outcomes using the Reach, Effectiveness, Adoption, Implementation, Maintenance (RE-AIM) framework. ${ }^{24}$ These outcomes will be tracked continuously throughout the program, and we will leverage findings about these outcomes to inform each phase of In Our DNA SC expansion, as well as modifications to implementation strategies and adaptations to the program itself.

\subsection{Objectives and Aims}

The goal of this protocol is to describe the implementation process and strategies to support In Our DNA $S C$. Incorporating implementation and evaluation theories and methods as part of the program's efforts from the beginning will help facilitate this population-wide genomic screening initiative at MUSC, as well as support initiatives across other health systems.

Aim 1: Monitor participation in In Our DNA SC and identify factors associated with participant engagement throughout each aspect of the program

Aim 2: Assess contextual factors and strategies that may influence adoption and sustainment of In Our DNA SC among clinical and community sites and ongoing site-specific needs related to program implementation

Aim 3: Describe facilitators and barriers to implementation and perceptions of In Our DNA SC among work groups 
Aim 4: Track adaptations made to In Our DNA SC over time to assess how mechanisms of change impact key programmatic outcomes

\section{Methods/design}

\subsection{Overall Study Design}

To achieve our four implementation focused aims, we will use a convergent parallel mixed-methods study design to assess the planned implementation strategies and the effectiveness of In Our DNA SC. This approach will allow us to simultaneously collect quantitative and qualitative data, merge the data, and use the results to provide a comprehensive understanding of the implementation of In Our DNA SC. We will use rapid assessments of the implementation strategies (e.g., fidelity checks, training, and technical assistance) to inform changes to the intervention. Additionally, our design will track planned incidental adaptations made throughout the program. ${ }^{25}$

We will use the expanded CONSORT diagram to standardize internal reporting and produce rapid, rigorous, transparent, and relevant information. ${ }^{26,27}$

\subsection{Data Collection Strategies}

We currently plan to collect data from ten sources. These strategies include a data dashboard, participant interviews, use of training materials, implementation site logs, site readiness surveys, work group logs, adaptation logs, research coordinator logs, and check-in surveys.

Data Dashboard. Monitoring participant recruitment and sample collection will take place through a Data Dashboard in the electronic health record. The Data Dashboard includes summary information about: total number of recruitment messages sent, declined, non-response, express interest, enrolled, samples collected, sample re-collection (original sample was not sufficient), results sent to Helix, results returned to the participant, number of positive individuals who complete genetic counseling, and number who schedule additional screening. Data will also be stratified by demographics, based on information available from the electronic health record, including: age, sex, race, ethnicity, education, income, and area of residence.

Participant Interviews. Qualitative data will also be collected to further probe in areas of significant drop off or where there are discrepancies in the anticipated and actual numbers of individuals based on demographic categories. Current areas identified for qualitative investigation include: a) individuals who do not enroll in In Our DNA SC either because they decline or review the invitation to participate and take no action, b) people who participate in In Our DNA SC and receive negative results, and c) people who participate in In Our DNA SC and receive positive results. Individuals will be invited to participate in brief interviews via phone or email. The interview questions will be guided by a semi-structure interview guide tailored to the type of individual being interviewed. We will focus on recruiting diverse individuals to capture perceptions about genetics. We will conduct interviews every six-months throughout the duration of the program (anticipated to be 48 months).

Use of Training Materials. A major aspect to successful implementation of In Our DNA SC involves saliva sample collection. We will assess the contextual factors and strategies that influence how samples are being 
collected. These training materials and sample collection occurs only among clinical sites affiliated with MUSC. Data collection about use of training materials includes tracking the use of training materials available sites through MyQuest (internal training site) and Horseshoe (internal website). Data will be captured prior to implementation at a site using quantitative methods.

Use of Community-facing Education Materials. To help support engagement of historically underrepresented populations in genomics research, the In Our DNA SC program will develop educational materials to be delivered in community settings (e.g., via community health workers and other public health workforces). We will assess the impact these materials have on individual's perceptions and understanding of genetics.

Implementation Site Logs. Qualitative data will also be by tracking weekly technical assistance calls with implementation sites and coding these meetings using CFIR with a focus on: executing, participant needs and resources, implementation climate, and leadership engagement. ${ }^{22}$ The logs have space to capture open ended notes about these discussions.

Site Readiness Survey. We will assess readiness for implementation and perceptions of the program using quantitative measures of Acceptability of Intervention Measure (AIM), Intervention Appropriateness Measure (IAM), and Feasibility of Intervention Measure (FIM) and open-ended response options. ${ }^{28}$ These surveys are distributed prior to implementation at new clinical and community sites.

Work Group Logs. Work Group Logs are a RedCap survey used to capture notes at each scheduled work group meeting. Information captured includes: date of meeting, overview of the topics discussed, and option to save key documents provided during the meeting. Immediately following each work group meeting, the study team will use the RedCap survey to identify which components of CFIR were addressed as part of the Work Group Log and whether these elements are considered facilitators or barriers.

Adaptation Logs. Adaptation Logs gather data about the changes being made to the In Our DNA SC program. Adaptation tracking includes a brief description of the adaptation made, whether it was planned or unplanned, when in the program the adaptation was made, what changed (e.g., content, context, training), the nature of the modification (e.g., tailoring, repeating a component of the intervention, changing order of components of intervention), who initiated (e.g., leadership, specific work group, stakeholder), who the change impacts (e.g., patient, implementation teams), the basis on which the changes were made (e.g., based on summary information, financial incentives), why the change was made (e.g., to increase reach, to improve adoption), the impact of the change (e.g., positive, negative), and long term impact of the change (e.g., increase reach, improve participation by teams, improved ability to deliver intervention successfully). ${ }^{23,29-31}$

Research Coordinator Logs. Research Coordinator Logs will capture questions and technical assistance needs from participants, clinicians and providers, and implementation teams. Details about the type of question and whether follow-up is needed are included in the research coordinator log.

Check-in Surveys. Check-in Surveys will be sent to implementation teams (work group members) prior to the launch of a new phase of the program to capture their experience with In Our DNA SC. These surveys assess how confident implementation teams are in the status of the program using the RE-AIM framework. ${ }^{24}$ 


\subsection{Qualitative Data Analysis}

Participant Interviews. Interviews will be transcribed and quality controlled. We will initially conduct rapid qualitative analysis to provide necessary information to inform ongoing program development. Rapid qualitative analysis involves developing a templated summary table to extract interview data, including illustrative quotes for each interview. Next, the interview summaries are consolidated by participant type in a data matrix to capture themes, sub-themes, and supporting quotes. Data from this step will be used to report to program leadership and optimize implementation. ${ }^{32}$ Full, in-depth coding will occur using thematic analysis at program completion.

Implementation Site Logs. In Our DNA SC operational staff provides weekly implementation calls where sites implementing the program gather to discuss questions and concerns about the program implementation. A member of the study team participates in these weekly calls and tracks facilitators and barriers to implementation using a RedCap tracking tool that includes space to take notes about the facilitators and barriers identified and CFIR themes. Initial qualitative analyses are conducted in real-time. Themes will be reported in summary across sites. This rapid deductive approach allows for us to capture information in realtime to help inform the process of implementation. ${ }^{33}$ Once coded, the information from the implementation site logs are used as quantitative data in Aim 2.

Work Group Logs. Similar to implementation site logs, Work Group Logs will be immediately coded in real-time. CFIR facilitators and barriers will be recorded and summarized by work group and in summary across work groups. This rapid deductive approach allows for us to capture information in real-time to help inform the process of implementation. Once coded the work group logs are used as quantitative data in Aim 3.

\subsection{Quantitative Data Analysis}

Descriptive analyses will be performed prior to conducting statistical analyses for each aim.

\section{Aim 1: Monitor participation in In Our DNA SC and identify factors associated with participant engagement throughout each aspect of the program}

The primary outcomes of interest for Aim 1 are at the individual level and include reach (total number of eligible people reached based on recruitment messages, declined, non-response, express interest, and enrollment), implementation (number of samples collected, re-collected, and results sent), effectiveness/efficacy (positive patients who complete program, positive patients who follow-up with genetic counselor).

Predictors for the primary data analysis include information collected through the Data Dashboard described above, including: demographics (age, sex, race, ethnicity, education, income, and area of residence).

All primary outcomes of interest related to Aim 1 are continuous and measured at the individual level. We will use simple linear regression to assess for bivariate associations between all demographic predictors on each continuous outcome of interest. We will also conduct multivariable linear regression to assess the influence of all demographic characteristics and fixed covariates for each collection site as predictors of each outcome. Data will be reported weekly as well as longitudinally to assess for trends in each outcome over time. 
The primary outcomes of interest include adoption (total number of MUSC and community sites enrolling participants, differences in adoption across sites in South Carolina) and maintenance (sites that continue to promote population-wide genomic screening beyond initial funding period).

Predictors used to assess for outcomes related to Aim 2 include the use of training materials, implementation site logs (number and type of facilitators and barriers identified), research coordinator logs (number and type of questions asked), site readiness (AIM, IAM, FIM), and community-facing materials. ${ }^{28}$

All outcomes and predictors are assessed at the site level. We will conduct bivariate analyses using simple linear or logistic regression with outcomes of interest. We will also use multivariable linear regression to assess the influence of all predictors on outcomes of interest at the clinical and community site levels.

\section{Aim 3: Describe facilitators and barriers to implementation and perceptions of In Our DNA SC among implementation work groups}

We will summarize the implementation barriers and facilitators identified during each work group meeting as part of the work group logs. These will be reported stratified by work group and summarized across all work groups. We will assess changes in facilitator and barriers longitudinally across the program. In addition, we will summarize perceptions of In Our DNA SC using findings from the check-in survey. Findings will be stratified by work group and in summary. Additionally, we will assess change in perceptions longitudinally across the program.

\section{Aim 4: Track adaptations made to In Our DNA SC over time to assess how mechanisms of change impact key programmatic outcomes}

All quantitative data captured through the adaptation tracking logs will be regularly assessed through descriptive analyses. Information from each log will be reported in aggregate (e.g., types of adaptations made, key CFIR facilitators and barriers identified in work group logs) on an ongoing basis. The longitudinal tracking will allow the team to assess various mediators and moderators of program outcomes.

The data collected as part of Aim 4 is primarily designed to provide structure to track the roll out of In Our DNA $S C$ and to capture the implementation over time. We will develop additional tracking tools as needed over the course of program implementation.

\subsection{Integrating Quantitative and Qualitative Methods}

Across all aims, data will be integrated to provide rapid feedback to the implementation teams and leadership overseeing the implementation of In Our DNA SC. We will closely monitor factors that influence DEI and representation of racial and ethnic minorities in the program. Reported barriers and facilitators will be matched with evidence-based mechanisms of change and implementation strategies to quickly resolve implementation barriers and tailor implementation strategies to be suitable for groups that have historically been excluded from genetic research. ${ }^{29}$ We will continue to use this approach of rapid assessment and intervention 
modification throughout the stages of program implementation and adjust our approaches to monitoring participation as needed.

\section{Discussion}

This implementation research seeks to leverage the existing infrastructure and implementation efforts of In Our DNA SC, a population-wide genomic screening initiative to assess both implementation and effectiveness outcomes. Our goal is to continuously provide feedback to support the implementation and sustainability of In Our DNA SC, which can enable precision-based clinical engagement of subpopulations who could benefit most. Information gathered during this study will help provide a foundation for additional research needed to support population-wide genomic screening and efforts to integrate routine genetic screening into clinical practice.

A major goal of In Our DNA SC is to engage the diverse populations of South Carolina. According to the 2020 United States Census Bureau, approximately $69 \%$ of South Carolinians identify as White, $27 \%$ as Black or African American, $6 \%$ as Some Other Race, and $6 \%$ as Two or More Races. ${ }^{34}$ Inclusion of historically underrepresented and diverse groups, understanding their preferences towards genomic testing, and assessing the role of tailored educational strategies in improving participant engagement, are unique strengths of In Our $D N A S C$. Results from this program are expected to enhance diversity and help mitigate the health disparities and inequities resulting from lack of diversity in genomics research. Given the emphasis of In Our DNA SC in diversity and inclusion of historically underrepresented or marginalized populations, and the legacy of misuse and misapplication of genetic research in certain groups and communities, special attention is being given to ELSI of this initiative to local communities.

We use a pragmatic approach to collection and analysis of quantitative and qualitative data. For example, we use a rapid qualitative analysis method to initially assess patient interviews. This study captures data in realtime, allowing us to inform the direction of the program and match implementation strategies to key barriers. Further, our approach to studying the program is guided by a strong conceptual framework that incorporates well-recognized implementation science theories of RE-AIM and CFIR. ${ }^{22,24}$

Our planned implementation research activities are not without limitations. The In Our DNA SC initiative was designed to be implemented in a dynamic way with various phases of staging and growth. While the general outline of how the program will be expanded exists (e.g., pilot phase, additional clinical site, and community site expansion), as the study team implements each phase the exact way that each phase is implemented may change. Our study seeks to account for how these changes impact the key outcomes through close tracking using the Adaptation Log; however, additional tools or methodologies and analyses we have not accounted for in the current protocol may be needed to assess the program as it grows. Additionally, our most distal clinical effectiveness outcome is whether a positive individual who are at high risk for HBOC, LS, or FH complete genetic counseling and scheduling recommended follow-up screening. We do not assess for the clinical management and long-term adherence to recommendations for the management of high-risk individuals (e.g., oophorectomy for those identified with $\mathrm{HBOC}$ ). Additional efforts are needed to track clinical management and cascade screening of identified families. These limitations suggest the need for future efforts to continue building evidence about the clinical utility of population-wide genomic screening. 
We have developed a series of research questions and associated data collection tools to assess factors that may influence the implementation of population-wide genomic screening among individuals, clinical staff and providers, and implementation teams. These efforts focus on ensuring access to this program among populations that have historically been excluded in genetic research and clinical services. Our pragmatic approach to studying how a population-based effort is implemented in a health system can support generalization of the lessons from In Our DNA SC and identify best practices to streamline expansion of similar initiatives at in other settings.

\section{Declarations}

Elissa Levine and Catherine Clinton are employees of Helix. All other authors have no additional conflicts of interest to declare.

\section{References}

1. Khoury MJ, Bowen MS, Clyne M, et al. From public health genomics to precision public health: a 20year journey. Genetics in medicine : official journal of the American College of Medical Genetics. 2018;20(6):574-582.

2. Smith CE, Fullerton SM, Dookeran KA, et al. Using Genetic Technologies To Reduce, Rather Than Widen, Health Disparities. Health Aff (Millwood). 2016;35(8):1367-1373.

3. Manickam K, Buchanan AH, Schwartz MLB, et al. Exome Sequencing-Based Screening for BRCA1/2 Expected Pathogenic Variants Among Adult Biobank Participants. JAMA Netw Open. 2018;1(5):e182140.

4. Saadatagah S, Jose M, Dikilitas $\mathrm{O}$, et al. Genetic basis of hypercholesterolemia in adults. NPJ Genom Med. 2021;6(1):28-28.

5. Win AK, Jenkins MA, Dowty JG, et al. Prevalence and Penetrance of Major Genes and Polygenes for Colorectal Cancer. Cancer epidemiology, biomarkers \& prevention : a publication of the American Association for Cancer Research, cosponsored by the American Society of Preventive Oncology. 2017;26(3):404-412.

6. Austin MA, Hutter CM, Zimmern RL, Humphries SE. Genetic causes of monogenic heterozygous familial hypercholesterolemia: a HuGE prevalence review. American journal of epidemiology. 2004;160(5):407420 .

7. Acton RT, Burst NM, Casebeer $\mathrm{L}$, et al. Knowledge, attitudes, and behaviors of Alabama's primary care physicians regarding cancer genetics. Academic medicine : journal of the Association of American Medical Colleges. 2000;75(8):850-852.

8. National Instututes of Health. National Institutes of Health State-of-the-Science Conference Statement Family History and Improving Health. National Institutes of Health;2009.

9. Rich EC, Burke W, Heaton CJ, et al. Reconsidering the family history in primary care. J Gen Intern Med. 2004;19(3):273-280. 
10. Williams JL, Collingridge DS, Williams MS. Primary care physicians' experience with family history: an exploratory qualitative study. Genetics in medicine : official journal of the American College of Medical Genetics. 2011;13(1):21-25.

11. American Medical Association. Family Medical History in Disease Prevention. 2018.

12. Gabai-Kapara E, Lahad A, Kaufman B, et al. Population-based screening for breast and ovarian cancer risk due to BRCA1 and BRCA2. Proc Natl Acad Sci U S A. 2014;111(39):14205-14210.

13. Buchanan AH, Rahm AK, Williams JL. Alternate Service Delivery Models in Cancer Genetic Counseling: A Mini-Review. Front Oncol. 2016;6:120-120.

14. Buchanan AH, Lester Kirchner H, Schwartz MLB, et al. Clinical outcomes of a genomic screening program for actionable genetic conditions. Genetics in medicine : official journal of the American College of Medical Genetics. 2020;22(11):1874-1882.

15. Abul-Husn NS, Soper ER, Braganza GT, et al. Implementing genomic screening in diverse populations. Genome Med. 2021;13(1):17.

16. Murray MF, J. P. Evans, M. Angrist, K. Chan, W. Uhlmann, D. L. Doyle, S. M. Fullerton, T. Ganiats, J. Hagenkord, S. Imhof, S. H. Rim, L. Ortmann, N. Aziz, W. D. Dotson, E. Matloff, K. Young, K. Kaphingst, A. Bradbury, J. Scott, C. Wang, A. Zauber, M. Levine, B. Korf, D. Leonard, C. Wicklund, G. Isham, and M. J. Khoury. A Proposed Approach for Implementing Genomics-Based Screening Programs for Healthy Adults. NAM Perspectives DIscussion Paper. 2018.

17. Selby K, Bartlett-Esquilant G, Cornuz J. Personalized cancer screening: helping primary care rise to the challenge. Public Health Rev. 2018;39:4.

18. Rebbeck TR, Burns-White K, Chan AT, et al. Precision Prevention and Early Detection of Cancer: Fundamental Principles. Cancer Discov. 2018;8(7):803-811.

19. Roberts MC, Kennedy AE, Chambers DA, Khoury MJ. The current state of implementation science in genomic medicine: opportunities for improvement. Genetics in medicine : official journal of the American College of Medical Genetics. 2017;19(8):858-863.

20. Chambers DA, Feero WG, Khoury MJ. Convergence of Implementation Science, Precision Medicine, and the Learning Health Care System: A New Model for Biomedical Research. Jama. 2016;315(18):1941-1942.

21. Tabak RG, Khoong EC, Chambers DA, Brownson RC. Bridging research and practice: models for dissemination and implementation research. American journal of preventive medicine. 2012;43(3):337-350.

22. Damschroder LJ, Aron DC, Keith RE, Kirsh SR, Alexander JA, Lowery JC. Fostering implementation of health services research findings into practice: a consolidated framework for advancing implementation science. Implementation science : IS. 2009;4:50. 
23. Bunger AC, Powell BJ, Robertson HA, MacDowell H, Birken SA, Shea C. Tracking implementation strategies: a description of a practical approach and early findings. Health Res Policy Syst. 2017;15(1):15.

24. Glasgow RE, Vogt TM, Boles SM. Evaluating the public health impact of health promotion interventions: the RE-AIM framework. American journal of public health. 1999;89(9):1322-1327.

25. Landes SJ, McBain SA, Curran GM. An introduction to effectiveness-implementation hybrid designs. Psychiatry Res. 2019;280:112513.

26. Glasgow RE, Chambers D. Developing robust, sustainable, implementation systems using rigorous, rapid and relevant science. Clin Trans/ Sci. 2012;5(1):48-55.

27. Glasgow RE, Huebschmann AG, Brownson RC. Expanding the CONSORT Figure: Increasing Transparency in Reporting on External Validity. American journal of preventive medicine. 2018;55(3):422-430.

28. Weiner BJ, Lewis CC, Stanick C, et al. Psychometric assessment of three newly developed implementation outcome measures. Implementation science : IS. 2017;12(1):108.

29. Boyd MR, Powell BJ, Endicott D, Lewis CC. A Method for Tracking Implementation Strategies: An Exemplar Implementing Measurement-Based Care in Community Behavioral Health Clinics. Behav Ther. 2018;49(4):525-537.

30. McCarthy MS, Ujano-De Motta LL, Nunnery MA, et al. Understanding adaptations in the Veteran Health Administration's Transitions Nurse Program: refining methodology and pragmatic implications for scale-up. Implementation science : IS. 2021;16(1):71.

31. Rabin BA, McCreight M, Battaglia C, et al. Systematic, Multimethod Assessment of Adaptations Across Four Diverse Health Systems Interventions. Frontiers in public health. 2018;6:102.

32. Gale RC, Wu J, Erhardt T, et al. Comparison of rapid vs in-depth qualitative analytic methods from a process evaluation of academic detailing in the Veterans Health Administration. Implementation science : IS. 2019;14(1):11.

33. Nevedal AL, Reardon CM, Opra Widerquist MA, et al. Rapid versus traditional qualitative analysis using the Consolidated Framework for Implementation Research (CFIR). Implementation science : IS. 2021;16(1):67.

34. America Counts Staff. South Carolina Gained Almost Half a Million People Last Decade. https://www.census.gov/library/stories/state-by-state/south-carolina-population-change-between-censusdecade.html. Published 2021. Accessed.

\section{Tables}

\section{Table 1. Data Collection Strategies}




\begin{tabular}{|c|c|c|c|c|}
\hline Strategy & Description & Frequency & $\begin{array}{l}\text { Type of } \\
\text { Data }\end{array}$ & $\begin{array}{l}\text { Use } \\
\text { (Aim) }\end{array}$ \\
\hline $\begin{array}{l}\text { Data } \\
\text { Dashboard }\end{array}$ & $\begin{array}{l}\text { - Recruitment messages sent } \\
\text { - Declined } \\
\text { - Non-response } \\
\text { - Expressed interest } \\
\text { - Enrolled } \\
\text { - Samples collected } \\
\text { - Re-collection needed } \\
\text { - Results sent to Helix } \\
\text { - Demographics (age, sex, race, } \\
\text { ethnicity, education, income, area of } \\
\text { residence) }\end{array}$ & Ongoing & Quantitative & Aim 1 \\
\hline $\begin{array}{l}\text { Participant } \\
\text { Interviews }\end{array}$ & $\begin{array}{l}\text { Semi-structured interview guide to } \\
\text { qualitatively assess experience of } \\
\text { individuals who are part of In Our DNA } \\
\text { SC }\end{array}$ & $\begin{array}{l}\text { Every 6-months } \\
\text { throughout } \\
\text { duration of } \\
\text { program }\end{array}$ & Qualitative & Aim 1 \\
\hline $\begin{array}{l}\text { Use of Training } \\
\text { Materials }\end{array}$ & $\begin{array}{l}\text { - View pre-recorded training } \\
\text { materials } \\
\text { - Download brochures and handouts }\end{array}$ & $\begin{array}{l}\text { During training } \\
\text { period for sites } \\
\text { (pre- } \\
\text { implementation) }\end{array}$ & Quantitative & Aim 2 \\
\hline $\begin{array}{l}\text { Implementation } \\
\text { site logs }\end{array}$ & $\begin{array}{l}\text { Tracking of technical assistance calls } \\
\text { with implementation sites; coded with } \\
\text { CFIR to track facilitators and barriers }\end{array}$ & Weekly meetings & $\begin{array}{l}\text { Quantitative } \\
\text { (open ended } \\
\text { questions) }\end{array}$ & $\operatorname{Aim~}_{2}$ \\
\hline $\begin{array}{l}\text { Site Readiness } \\
\text { Survey }\end{array}$ & $\begin{array}{l}\text { Assessment of readiness for } \\
\text { implementation and perceptions of the } \\
\text { program using AIM, IAM, and FIM }\end{array}$ & $\begin{array}{l}\text { Pre- } \\
\text { implementation }\end{array}$ & $\begin{array}{l}\text { Quantitative } \\
\text { (open ended } \\
\text { questions) }\end{array}$ & $\begin{array}{l}\text { Aim 1, } \\
2\end{array}$ \\
\hline $\begin{array}{l}\text { Work group } \\
\text { logs }\end{array}$ & $\begin{array}{l}\text { Tracking of working group meetings and } \\
\text { progress; coded using CFIR to track } \\
\text { facilitators and barriers }\end{array}$ & Weekly meetings & $\begin{array}{l}\text { Quantitative } \\
\text { (open ended } \\
\text { questions) }\end{array}$ & Aim 3 \\
\hline $\begin{array}{l}\text { Adaptation } \\
\text { logs }\end{array}$ & $\begin{array}{l}\text { Tracking of changes made throughout } \\
\text { the course of implementation and } \\
\text { outcomes associated with change }\end{array}$ & $\begin{array}{l}\text { Ongoing/as } \\
\text { adaptations are } \\
\text { made }\end{array}$ & $\begin{array}{l}\text { Quantitative } \\
\text { (open ended } \\
\text { questions) }\end{array}$ & Aim 4 \\
\hline $\begin{array}{l}\text { Research } \\
\text { coordinator } \\
\text { logs }\end{array}$ & $\begin{array}{l}\text { Tracking of questions and technical } \\
\text { assistance needs from: patients, } \\
\text { clinicians, providers, implementation } \\
\text { teams }\end{array}$ & Ongoing & Quantitative & $\begin{array}{l}\text { Aim 1, } \\
2\end{array}$ \\
\hline $\begin{array}{l}\text { Check-in } \\
\text { surveys }\end{array}$ & $\begin{array}{l}\text { Periodic surveys sent to work group } \\
\text { members to capture experience and } \\
\text { provide barriers and facilitators using } \\
\text { RE-AIM framework }\end{array}$ & $\begin{array}{l}\text { Pre-launch of } \\
\text { new phase of } \\
\text { program }\end{array}$ & $\begin{array}{l}\text { Quantitative } \\
\text { (open ended } \\
\text { questions) }\end{array}$ & Aim 3 \\
\hline
\end{tabular}


Table 2. Summary of Implementation Aims 


\begin{tabular}{|c|c|c|c|c|}
\hline \multirow[t]{2}{*}{ Aim } & \multicolumn{3}{|c|}{ Quantitative Analyses } & \multirow{2}{*}{$\begin{array}{l}\text { Qualitative } \\
\text { Analyses }\end{array}$} \\
\hline & $\begin{array}{l}\text { Analysis Unit and } \\
\text { Method }\end{array}$ & $\begin{array}{l}\text { Primary } \\
\text { Predictors }\end{array}$ & Outcomes (RE-AIM) & \\
\hline $\begin{array}{l}\text { Aim 1: Monitor } \\
\text { participation in } \\
\text { In Our DNA SC } \\
\text { and identify } \\
\text { factors } \\
\text { associated with } \\
\text { participant } \\
\text { engagement } \\
\text { throughout } \\
\text { each aspect of } \\
\text { the program }\end{array}$ & $\begin{array}{l}\text { Analysis Unit: } \\
\text { Individual } \\
\text { Analysis Method: } \\
\text { All outcomes } \\
\text { assessed cross- } \\
\text { sectional (weekly } \\
\text { reports to } \\
\text { leadership) and } \\
\text { longitudinally }\end{array}$ & $\begin{array}{l}\text { Demographics: } \\
\text { - Age } \\
\text { - Sex } \\
\text { - Race } \\
\text { - Ethnicity } \\
\\
\text { Collection Site }\end{array}$ & $\begin{array}{l}\text { Reach: } \\
\text { - \# of eligible } \\
\text { individuals } \\
\text { reached } \\
\text { - \# viewed } \\
\text { recruitment } \\
\text { message } \\
\text { - \# declined } \\
\text { - \# non-response } \\
\text { - \# expressed } \\
\text { interest } \\
\text { - \# enrolled } \\
\\
\text { Implementation: Among } \\
\text { those enrolled in In Our } \\
\text { DNA SC. } \\
\text { - \# of samples } \\
\text { collected } \\
\text { - \# Re-collected } \\
\text { - \# Results sent } \\
\text { Timeliness of } \\
\text { return of results } \\
\text { - High-risk } \\
\text { management of } \\
\text { positive patients } \\
\text { (number of people } \\
\text { visiting genetic } \\
\text { counselor who } \\
\text { schedule } \\
\text { screening) } \\
\text { Effectiveness/Efficacy: } \\
\text { - Number of people } \\
\text { who complete In } \\
\text { Our DNA SC } \\
\text { wositive patients } \\
\text { gho follow-up with } \\
\text { genetic counselor } \\
\\
\text { Maintenance: } \\
\text { - }\end{array}$ & $\begin{array}{l}\text { Participant } \\
\text { Interviews } \\
\text { - Efficacy. } \\
\text { Participant } \\
\text { experiences } \\
\text { and } \\
\text { satisfaction } \\
\text { with } \\
\text { program } \\
\text { - Rapid } \\
\text { analysis } \\
\text { initially to } \\
\text { provide } \\
\text { necessary } \\
\text { information } \\
\text { - Full, in- } \\
\text { depth } \\
\text { coding } \\
\text { using } \\
\text { thematic } \\
\text { analysis } \\
\text { approach } \\
\text { - Participants } \\
\text { stratified } \\
\text { based on } \\
\text { type of } \\
\text { engagement } \\
\text { (declined, } \\
\text { non- } \\
\text { response, } \\
\text { enrolled) }\end{array}$ \\
\hline
\end{tabular}


Aim 2: Assess contextual

factors and strategies that may influence adoption and sustainment of In Our DNA SC among clinical and community sites and ongoing sitespecific needs related to program implementation
Analysis Unit:

Site

Use of Training Materials

Analysis Method:

Bivariate analyses and multivariable linear regression to assess influence of predictors on adoption and maintenance
Use of communityfacing education materials

Implementation Site Logs (number and type of facilitators and barriers identified)

Research coordinator logs (number and type of question)

Site Readiness

Survey (AIM, IAM, FIM)
Adoption:

- Total number of MUSC and community sites enrolling

- Differences in adoption across SC

Maintenance: Site that In Our DNA SC is continued
Implementation Site Logs: Rapid deductive qualtiative analysis
Aim 3: Describe facilitators and barriers to implementation work groups and perceptions of In Our DNA SC among work groups

\section{Analysis Unit:}

Work Group, Implementation Team

\section{Analysis} Method: Frequency and Percent, Mean and Standard Deviation; Cross sectional and longitudinal
Aim 4: Track adaptations made to In Our DNA SC over time to assess how mechanisms of change impact key programmatic outcomes

\section{Analysis Unit:} Program

Analysis Method:

Summary of type of adaptations made
Work Group Logs: Summarize implementation barriers and facilitators by work group and over time

Check in survey: Summarize perception of program by work group and over time
Work Group

Logs: Rapid

deductive qualitative analysis 
Figures
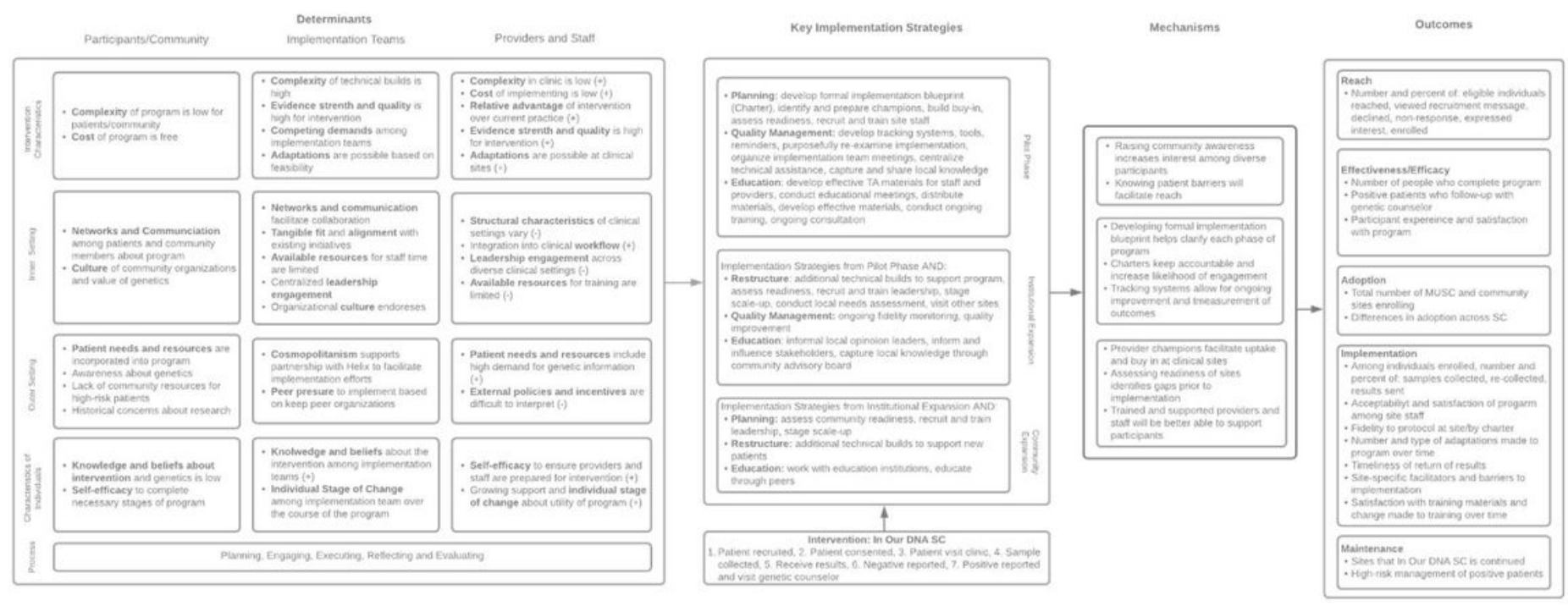

\section{Figure 1}

\section{Conceptual Model}




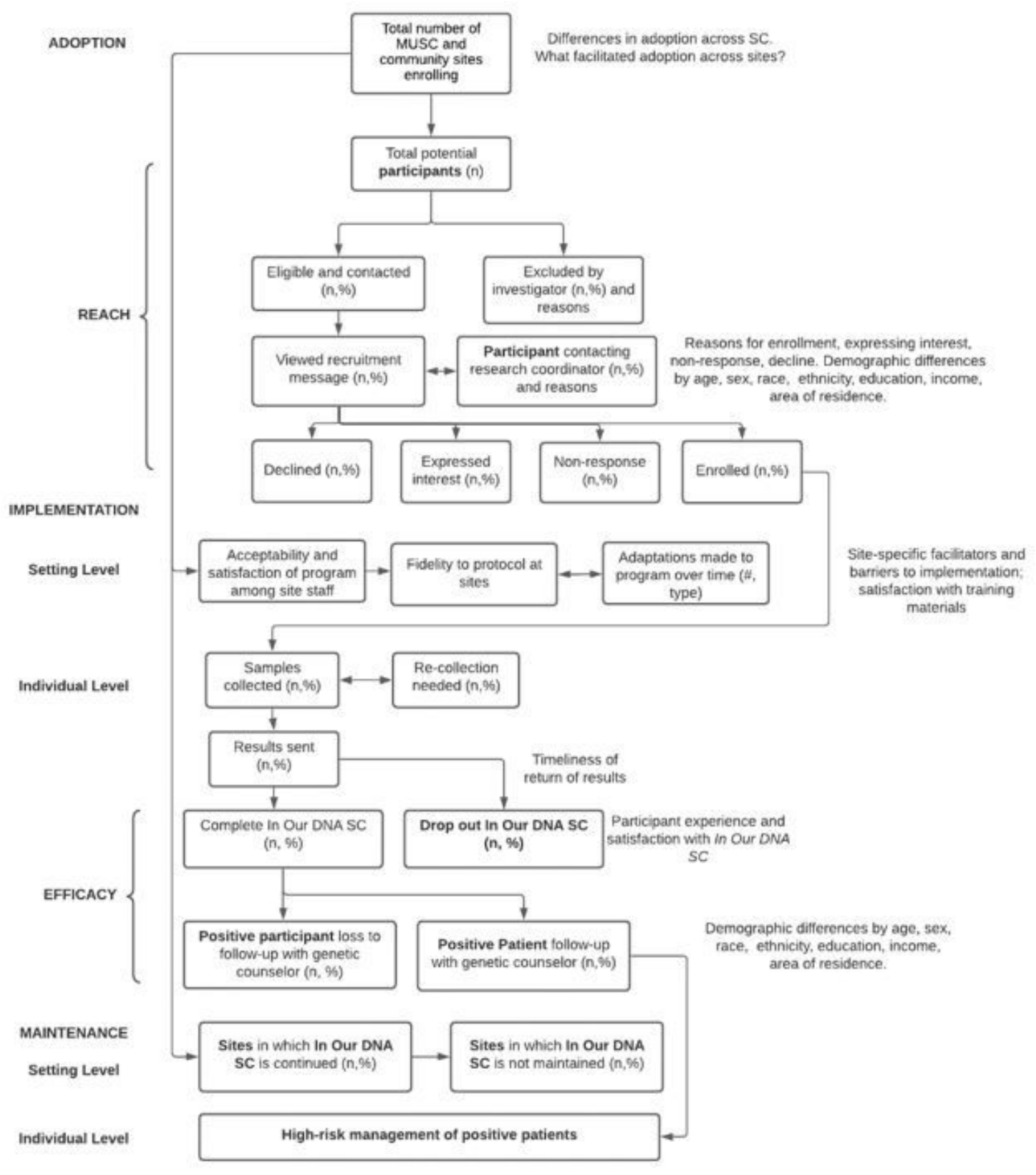

Figure 2

CONSORT Diagram 